\title{
PENGETAHUAN DAN KEPATUHAN MINUM TABLET TAMBAH DARAH PADA REMAJA PUTRI
}

\author{
Nengah Runiari ${ }^{1}$ Nyoman Hartati ${ }^{2}$ \\ ${ }^{1,2}$ Prodi Ners Jurusan Keperawatan Poltekkes Kemenkes Denpasar \\ Denpasar, Bali, Indonesia \\ e-mail:runiarijkp@gmail.com ${ }^{1}$,ninyomanhartati@gmail.com²
}

\begin{abstract}
The relationship between knowledge and adherence to drinking blood supplemented tablets for young women. The aim of this study was to determine the relationship between knowledge and adherence to taking blood supplemented tablets for girls. The research design was correlational analytic with cross sectional approach. The number of samples was 149 students of class XI SMA 6 Denpasar who were selected by total sampling technique. The instruments used in this study were a knowledge questionnaire and the MMAS-8 (Morisky Medication Adherence Scale) to measure adherence to taking blood supplemented tablets. The results showed that the knowledge level of the respondents was mostly in the good enough category as much as $44.3 \%$. It was found that $21.5 \%$ of respondents had poor knowledge. The level of adherence of respondents to drink iron tablets was 87 people (58.4\%) with low adherence and 62 people (41.6\%) had moderate adherence. The results of the analysis with Kendall Tau found a p-value of 0.03, which means that there is a relationship between knowledge and adherence to taking blood supplement tablets. Furthermore, it is suggested to increase the involvement of parents in monitoring the drinking of iron tablets.
\end{abstract}

Keywords: Knowledge, Adherence, blood supplemented tablets, Young Women

\begin{abstract}
Abstrak :Hubungan Pengetahuan Dengan Kepatuhan Minum Tablet Tambah darah Pada Remaja Putri.Tujuan penelitian ini adalah mengetahui hubungan pengetahuan dengan kepatuhan meminum tablet tambah darah remaja putri. Disain penelitian adalah analitik korelasional dengan pendekatan crosssectional. Jumlah sampel 149 orang siswi kelas XI SMA 6 Denpasar yang dipilih dengan teknik total sampling. Instrumen yang digunakan dalam penelitian ini adalah kuisioner pengetahuan dan MMAS-8 (MoriskyMedicationAdherenceScale) untuk mengukur kepatuhan meminum tablet tambah darah. Hasil Penelitian menunjukkan bahwa tingkat pengetahuan responden paling banyak berada pada katagori cukup baik sebanyak 44.3\% . ditemukan masih ada sebanyak $21.5 \%$ responden dengan pengetahuan kurang baik. Tingkat kepatuhan responden minum TTD sebanyak 87 orang $(58.4 \%)$ dengan kepatuhan rendah dan sebanyak 62 orang (41.6\%) kepatuhan sedang. Hasil analisis dengan Kendall Tau ditemukan p value 0.03 artinya ada hubungan antara pengetahuan dengan kepatuhan meminum tablet tambah darah. Selanjutnya disarankan agar meningkatkan keterlibatan orang tua dalam melakukan pengawasan minum TTD.
\end{abstract}

Kata kunci: Pengetahuan, Kepatuhan, Tablet Tambah Darah, Remaja Putri 


\section{PENDAHULUAN}

Anemia merupakan masalah gizi global di seluruh dunia yang dialami oleh hampir seluruh kelompok usia dalam siklus kehidupan, mulai dari usia anak-anak, remaja, wanita usia subur (WUS) hingga ibu hamil. WHO menyatakansebanyak 528.4 jutawanitausia 15-49 tahun di seluruh dunia mengalami anemia pada tahun2011.Sekitar $50 \%$ kasus anemia yang terjadi di seluruh dunia disebabkan oleh defisiensizatbesi ${ }^{(1)}$.

Anemia adalah suatu kondisi tubuh dimana kadar hemoglobin $(\mathrm{Hb})$ dalam darah lebih rendah dari normal Anemia bila kadar hemoglobin darah menunjukkan nilai kurang dari $12 \quad \mathrm{~g} / \mathrm{dL}^{(2)}$. Anemia mempengaruhi setengah miliar wanita usia reproduksi di seluruh dunia. Pada tahun 2011, 29\% (496 juta) dari wanita yang tidak hamil dan $38 \%$ (32,4 juta) ibu hamil berusia 15-49 tahun mengalami anemia. Penyebab anemia bervariasi, diperkirakan separuh kasus disebabkan oleh defisiensi besi ${ }^{(3)}$.

Berdasarkan hasil Riset Kesehatan Dasar (Riskesdas) tahun 2013, prevalensi anemia ibu hamil $37,1 \%$ yang merupakan efek lanjutan dari tingginya prevalensi anemia pada remaja putri $(25 \%)$ dan Wanita Usia Subur $(17 \%)^{(4)}$. Anemia pada remaja putri dari $37,1 \%$ pada Riskedas 2013 mengalami peningkatan menjadi $48,9 \%$ pada Riskesdas 2018, dengan proporsi anemia ada di kelompok umur 15-24 tahun dan 25-34 tahun ${ }^{(5)}$.

Remaja putri pada masa pubertas sangat berisiko mengalami anemia gizi besi. Hal ini disebabkan banyaknya zat besi yang hilang selama menstruasi. Selain itu diperburuk oleh kurangnyaasupan zat besi, dimana zat besi pada rematri sangat dibutuhkan tubuh untuk percepatan pertumbuhan dan perkembangan (6). Anemia defisiensi besi dapat menimbulkan dampak pada remaja putri antara lain cepat lelah, menurunkan daya tahan tubuh terhadap penyakit infeksi, menurunkan kebugaran tubuh, menurunkan konsentrasi dan prestasi belajar. Selain itu dapat juga menurunkan sistem kekebalan tubuh serta mengganggu pertumbuhan fisik.

Anemia defisiensi besi pada masa remaja bukan saja menurunkan produktivitas tetapi pada gilirannya menggiring remaja putri pada kondisi anemia di masa kehamilan nanti. Ibu hamil yang menderita anemia akan mempertinggi risiko untuk mengalami keguguran, perdarahan waktu melahirkan, dan melahirkan bayi dengan berat lahir rendah (7)

Banyak factor penyebab terjadinya anemia. Penelitian yang dilakukan oleh ${ }^{(8)}$ menyatakan factor kebiasaan makan berpengaruh pada kejadian anemia. Penelitian lain menyatakan bahwa prilaku yaitu pengetahuan, sikap dan tindakan berpengaruh pada kejadian anemia (9). Penelitian yang dilakukan oleh (10) di Banglore, India menunjukkan hasil pre test pada 100 orang responden ditemukan pengetahuan masih rendah, sikap negatif dan praktik kurang baik.

Salah satu pencegahan utama anemia pada remaja putrid adalah dengan memperbaiki perilaku konsumsi pangan pada remaja, namun sangat sulit jika hanya melalui perbaikan konsumsi pangan. Remaja merupakan salah satu kelompok tertentu yang upaya peningkatan zat besinya tidak cukup jika hanya dengan perubahan perilaku konsumsi pangan. Oleh sebab itu, salah satu program penanggulangan yang dilakukan pemerintah adalah suplementasi tablet tambah darah ${ }^{(11)}$

Pemerintah telah menetapkan standar konsumsi tablet tambah darah demi mencegah kejadian anemia. Target cakupan remaja putri yang mendapatkan tablet tambah darah pada tahun 2016 adalah $15 \%$ dan pada tahun 2017 adalah $20 \%$ (12). Cakupan remaja putri usia 12-18 tahun yang mendapatkan tablet tambah darah di Indonesia hanya sebanyak $10.3 \%$ pada tahun 2016. Cakupan remaja putri usia 1218 tahun yang mendapatkan tablet tambah darah di Indonesia hanya sebanyak 12,4\% pada tahun $2017^{(13)}$. Berdasarkan hasil 
Riskesdas 2018, jumlah remaja putri yang mendapatkan tablet tambah darah sebanyak $76.2 \%$ dan jumlah remaja putri yang mendapatkan tablet tambah darah di sekolah sebanyak $80.9 \%{ }^{(5)}$.

Provinsi Bali memiliki cakupan remaja putri yang mendapatkan tablet tambah darah yaitu sebesar 95\% pada tahun 2018. Provinsi Bali terdiri dari Sembilan kabupaten dengan cakupan remaja putri yang mendapatkan tablet tambah darah terendah berada di Kabupaten Buleleng sebesar 74.5\%. Di Kota Denpasar, remaja putri yang mendapatkan tablet tambah darah baru mencapai 99\%. ${ }^{(14)}$. Berdasarkan hasil penelitian yang dilakukan oleh ${ }^{(15)}$ yang meneliti prevalensi anemia di Kota Denpasar pada tahun 2019 didapatkan kadar hemoglobin diukur dengan alat easytouch GCHb. Dari 74 orang yang diperiksa, ditemukan sebanyak 34 responden $(45,9 \%)$ mengalami anemia.

Pencegahan anemia dapat dilakukan dengan memperbaiki perilaku remaja putri. Salah satu faktor yang mempengaruhi prilaku remaja dalam pencegahan anemia adalah pengetahuan. Menurut penelitian yang dilakukan oleh ${ }^{(16)}$ pengetahuan yang kurang tentang tablet $\mathrm{Fe}$ akan mempengaruhi kepatuhan remaja putri. Kepatuhan remaja dalam minum tablet $\mathrm{Fe}$ sesuai anjuran dari petugas kesehatan sangat penting bagi remaja dalam mencegah anemia pada remaja.

\section{METODE}

Jenis penelitian yang digunakan adalah jenis penelitian korelasional dengan pendekatan crosssectional. Sampel dalam penelitian ini adalahsiswi SMA 6 Denpasar kelas XI sebanyak 149 orang dengan menggunakan teknik pengambilan sampel total sampling. Instrumen yang digunakan dalam penelitian terdiri dari kuisioner pengetahuan dan kepatuhan responden meminum tablet tambah darah menggunakan MMAS-8 (MoriskyMedicationAdherenceScale).Data yang sudah diolah, akan dianalisa dengan uji statistik Kendall Tau.

\section{HASILDANPEMBAHASAN}

Berdasarkan hasil pengumpulan data yang peneliti lakukan pada tanggal 7 Oktober sampai dengan 7 Nopember 2020 di SMA Negeri 6 Denpasar didapatkan sampel penelitian sebanyak 149 orang.

Tabel 1. KarakteristikResponden

\begin{tabular}{lcc}
\hline \multirow{2}{*}{ KarakteristikResponden } & \multicolumn{2}{c}{ Perlakuan } \\
& Jml & $\mathbf{\%}$ \\
& Jml \\
\hline Pendidikan terakhir Ibu & & \\
a. Tamat SD & 10 & 6.7 \\
b. Tamat SMP & 8 & 5.4 \\
c. Tamat SMA & 70 & 47 \\
d. Tamat PT & 61 & 40.1
\end{tabular}

Pekerjaan Ibu

\begin{tabular}{lll} 
a. Bekerja & 96 & 64.4 \\
b. TidakBekerja & 53 & 35.6 \\
\hline
\end{tabular}

Pendidikan terakhir Ayah

\begin{tabular}{|c|c|}
\hline a. Tamat SD & 6 \\
\hline b. Tamat SMP & 0 \\
\hline c. Tamat SMA & 51 \\
\hline d. Tamat PT & 92 \\
\hline
\end{tabular}

Pekerjaan

\begin{tabular}{|c|c|}
\hline Bekerja & 138 \\
\hline b. TidakBekerja & 11 \\
\hline
\end{tabular}

\begin{tabular}{lll}
\hline Penghasilan & & \\
a. $\quad<\mathrm{Rp} \mathrm{3.000.000}$ & 65 & 43.6 \\
b. $\operatorname{Rp~} 3.000 .0000-<\mathrm{Rp}$ & 59 & 39.6 \\
& 5.000 .0000 \\
c. $\operatorname{Rp~} 5.000 .0000-<\mathrm{Rp}$ & 17 & 11.4 \\
& 10.000 .000 \\
d. $\operatorname{Rp~} 10.000 .000$ & & \\
\hline
\end{tabular}

Berdasarkan tabel 2 diperoleh: pendidikan terakhir ibupaling banyak tamat SMA (47\%). Pekerjaan ibu paling banyak adalah bekerja. Pendidikan terakhir ayah sebanyak $61.8 \%$ tamat Perguruan Tinggi dan sebanyak $92.6 \%$ bekerja. Penghasilan orang tua paling banyak Rp 3.000.000-<Rp 5.000.000. 
Pengetahuan responden tentang anemia dapat dilihat pada tabel di bawah ini :

Tabel 2. Tingkat Pengetahuan Responden

Tentang Pencegahan Anemia

\begin{tabular}{lcc}
\hline $\begin{array}{l}\text { Tingkat } \\
\text { Pengetahuan }\end{array}$ & $\begin{array}{c}\text { Jml } \\
(\mathrm{n}=149)\end{array}$ & $\%$ \\
\hline Kurang Baik & 32 & 21.5 \\
Cukup Baik & 66 & 44.3 \\
Baik & 51 & 34.2 \\
\hline
\end{tabular}

BerdasarkanTabel 2, tingkat pengetahuan responden terbanyak berada pada tingkat pengetahuan cukup baik sebanyak 66 orang $(44.3 \%)$.

Hasil analisis berdasarkan jawaban responden didapatkan hampir $90 \%$ responden menjawab dengan benar pertanyaan tentang pengertian anemia, kadar hemoglobin remaja putrid dinyatakan anemia, penyebab terjadinya anemia, vitamin yang diminum untuk meningkatkan penyerapan zat besi, makanan dari hewani yang dapat mencegah anemia, mengapa remaja putri berisiko mengalami anemia dan berapa kali minum tablet tambah darah. Namun, hanya $60 \%$ responden menjawab dengan benar pertanyaan tentang tanda gejala anemia, akibat anemia, manfaat tablet tambah darah dan kapan waktu terbaik minum TTD.

Penelitian yang dilakukan oleh ${ }^{(17)}$ tentang hubungan factor social demografi dengan pengetahuan remaja putri tentang anemia menemukan sebagian besar $(64.9 \%)$ remaja perempuan diketahui memiliki pengetahuan yang kurang baik tentang program pemberian TTD sementara $35.1 \%$ ditemukan memiliki pengetahuan yang baik. Hasil Uji chi-square Pearson dengan ambang signifikansi $\mathrm{p} \quad<0.05$ diketahui bahwa tingkat pendidikan ibu ( $\mathrm{p}<0.02$ ), pekerjaan ibu ( $\mathrm{p}<0.04)$, dan pekerjaan ayah ( $\mathrm{p}<0.01)$ responden signifikan secara statistic berpengaruh terhadap tingkat pengetahuan remaja perempuan tentang program pemberian TTD. Responden yang ibunya memiliki pendidikan menengah 2.1 kali lebih mungkin memiliki pengetahuan yang baik tentang pencegahan anemia dan pemberian TTD.

Dalam penelitian ini, tingkat pengetahuan responden yang kurang baik didapatkan sebesar $21.5 \%$. Hasil penelitian ini berbeda dengan penelitian yang dilakukan oleh ${ }^{(18)}$ di SMA Negeri 1 Sukoharjo yang mendapatkan hasil sebagian besar remaja putri memiliki pengetahuan resiko anemia dengan kategori kurang $(61,1 \%)$. Kondisi ini dapat disebabkan karena penyuluhan tentang pencegahan anemia secara rutin dilakukan oleh Puskesmas II Denpasar Selatan di SMA 6 Denpasar. Sebelum terjadi pandemi Covid19, setiap minggu Penanggung jawab Gizi dari Puskesmas berkunjung ke sekolah dan bersama dengan penanggung jawab UKS sekolah memberikan penyuluhan dan membagikan TTD kepada siswi.

Tabel 3. Tingkat Kepatuhan Responden Meminum Tablet Tambah Darah

\begin{tabular}{lcc}
\hline Tingkat Kepatuhan & $\begin{array}{c}\text { Jml } \\
(\mathrm{n}=149)\end{array}$ & $\%$ \\
\hline Kepatuhan Rendah & 87 & 58.4 \\
Kepatuhan Sedang & 62 & 41.6 \\
\hline
\end{tabular}

Mengacu pada tabel 3 diketahui bahwa kepatuhan responden lebih banyak berada pada tingkat kepatuhan rendah sebanyak 87 orang $(58.4 \%)$ dan tidak ada responden dengan tingkat kepatuhan minum tablet tambah darah dengan katagori tinggi.

Dari delapan pernyataan yang terdapat dalam kuisioner MMAS-8 yang mengukur kepatuhan, hanya 40-50\% responden yang menjawab dengan benar. Sebagian besar responden menjawab "ya" untuk pernyataan Nomor 1, 4, 5, 6 dan 8 . Hal ini menunjukan bahwa tingkat kepatuhan responden dalam minum tablet tambah darah masih rendah.

Hasil penelitian ini hamper sama dengan penelitian yang dilakukan oleh Widiastuti ${ }^{(19)}$ yang menyatakan walaupun seluruh siswi telah mendapatkan paket tambah darah secara gratis. Namun tidak 
semua siswi menghabiskan tablet tambah darahnya. Siswi yang berada di perkotaan menghabiskan tablet tambah darah kurang dari $50 \%$. Siswi juga mengalami kendala dalam minum TTD, kendala yang dialami antara lain ada rasa mual, tidak suka dengan bau ataupun rasa. Dan kendala yang lain adalah adanya rasa malas serta beberapa merasa tidak perlu.

Banyak faktor yang mempengaruhi kepatuhan dalam meminum Tablet Tambah darah antara lain: pengetahuan, sikap, motivasi, dukungan orang tua dan dukungan guru. Berdasarkan penelitian yang dilakukan oleh Nuradhiani (20) determinan kepatuhan konsumsi TTD yang paling dominan berpengaruh pada remaja putrid adalah adanya dukungan guru $(\mathrm{p}<0,05$; $\mathrm{OR}=4,7 ; \quad 95 \% \mathrm{CI}: 1,5-14,2)$. Hal ini menunjukkan bahwa subjek yang mendapatkan dukungan guru dengan baik secara signifikan meningkatkan kepatuhan subjek 4.7 kali lebih besar untuk mengonsumsi TTD dibandingkan yang kurang mendapat dukungan dari guru.

Mengacu pada penelitian yang dilakukan oleh ${ }^{(21)}$ diperlukan promosi kesehatan dalam meningkatkan pengetahuan tentang anemia, pentingnya zat besi dan asam folat serta pengewasan yang berkala. Pengawasan dapat dilakukan dengan melakukan gerakan minum zat besi dan asam folat secara bersamaan pada waktu dan hari yang sama dengan langsung diawasi oleh guru di sekolah.

Menurut informasi dari Petugas Puskesmas II Denpasar Selatan, sebelum terjadinya Pandemi Covid-19, telah dilakukan gerakan setiap hari jumat siswi minum TTD di sekolah dengan pengawasan guru atau dikenal dengan Gemartersyantik (Gerakan Jumat dengan Pil Pintar sehat dan Cantik). Namun sejak pandemi Covid-19 tidak dapat terlaksana karena pembelajaran secara daring/online. Hal ini memerlukan kerja sama antara pihak sekolah dengan orang tua siswi untuk memantau remaja putri agar secara rutin meminum TTD.
Tabel 4. Hasil Analisis Hubungan

Pengetahuan dan Kepatuhan Meminum TTD

\begin{tabular}{lccc}
\hline $\begin{array}{l}\text { Tingkat } \\
\text { pengetahuan }\end{array}$ & \multicolumn{2}{c}{ Tingkat } & Jml \\
& kepatuhan & \\
& Rendah & Sedang & $\%$ \\
\hline Kurang baik & 24 & 8 & 32 \\
& $(16.1 \%)$ & $(5.4 \%)$ & $(21.5 \%)$ \\
Cukup baik & 41 & 25 & 66 \\
& $(27.5 \%)$ & $(16.8 \%)$ & $(44.3 \%)$ \\
Baik & 22 & 29 & 51 \\
& $(14.8 \%)$ & $(19.5 \%)$ & $(34.25)$ \\
\hline \multicolumn{4}{c}{} \\
& pvalue $=0.03$ & \\
&
\end{tabular}

Berdasarkan tabel 4, diketahui bahwa pada tingkat pengetahuan kurang baik didapatkan tngkat kepatuhan minum tablet tambah darah terbanyak pada katagori kepatuhan rendah, sebaliknya pada tingkat pengetahuan baik ditemukan paling banyak responden memiliki katagori kepatuhan sedang. Hasil uji dengan Kendall Tau ditemukan p value $0.03 \quad(<0.05)$ artinya ada hubungan yang signifikan antara tingkat pengetahuan dengan tingkat kepatuhan minum tablet tambah darah.

Penelitian lain yang mendukung dilakukan oleh ${ }^{(22)}$ yang meneliti tentang pengaruh media explanation video dalam pencegahan anemia remaja putrid terhadap pengetahuan dan kepatuhan konsumsi Tablet Tambah Darah di SMPN 65 Jakarta Utara. Hasil penelitian terdapat perbedaan tingkat pengetahuan dan kepatuhan konsumsi tablet tambah darah pada kelompok intervensi $(\mathrm{p} \leq 0,0001)$. Kelompok Kontrol sebelum dan sesudah intervensi tidak terdapat perbedaan tingkat pengetahuan dan kepatuhan konsumsi tablet tambah darah pada kelompokkontrol ( $\mathrm{p}>$ 0,083).

Kepatuhan (adherence) merupakan suatu bentuk perilaku yang timbul akibat adanya interaksi antara petugas kesehatan dan pasien sehingga pasien mengerti rencana dengan segala konsekwensinya dan 
menyetujui rencana tersebut serta melaksanakannya.

Dengan kepatuhan minum tablet tambah darah yang tinggi maka remaja putri akan terhindar dari anemia. Hasil penelitian ini sejalan dengan penelitian yang dilakukan oleh (23). Hasil analisis diperoleh pengetahuan gizi dan kepatuhan mengonsumsi tablet tambah darah memiliki hubungan signifikan dengan kejadian anemia masing-masing $\mathrm{p}$ valuenya 0.018 dan 0.0005 . Remaja putri yang memiliki pengetahuan baik $70.8 \%$ tidak mengalami anemia. Demikian juga remaja putri yang patuh mengonsumsi tablet tambah darah memiliki kadar hemoglobin di atas 11 gr/dL.

Sebuah studi cross-sectional dilakukan di antara 424 gadis remaja yang diambil secara acak di Tamale Metropolis of Ghana dari bulan April hingga Juli 2019 menggunakan kuesioner terstruktur yang diberikan pewawancara. Tingkat pendidikan dan pekerjaan ibu dari remaja putri, kesadaran tentang anemia dan pengetahuan yang baik tentang anemia dan tentang program pemberian TTD merupakan prediktor yang signifikan dari kepatuhan minum TTD. Mendidik remaja putri tentang anemia dan manfaat pemberian TTD dan melibatkan orang tua remaja putrid akan membantu meningkatkan tingkat kepatuhan remaja putrid dalam program pemberian $\operatorname{TTD}^{(17)}$.

\section{SIMPULAN}

Hasil penelitian menunjukan bahwa tingkat pengetahuan responden paling banyak berada pada katagori cukup baik sebanyak $44.3 \%$. ditemukan masih ada sebanyak $21.5 \%$ responden dengan pengetahuan kurang baik.

Tingkat kepatuhan responden minum TTD sebanyak 87 orang $(58.4 \%)$ dengan kepatuhan rendah. Hasil analisis dengan Kendall Tau ditemukan $p$ value 0.03 artinya ada hubungan antara pengetahuan dengan kepatuhan meminum tablet tambah darah.

\section{UCAPAN TERIMA KASIH}

Ucapan terima kasih disampaikan kepada Bapak Direktur Poltekkes Kemenkes Denpasar yang telah memberi kesempatan dan dukungan dana sehingga penelitian dapat berjalan dengan baik. Ucapan terima kasih juga disampaikan kepada Kepala SMA Negeri 6 Denpasar beserta staf yang telah memberikan ijin melakukan penelitian dan memfasilitasi peneliti melakukan pengumpulan data. Kepada Siswi SMA negeri 6 Denpasar yang telah berpartisipasi dalam penelitian ini juga diucapkan terimakasih.

\section{ETIKA PENELITIAN}

Penelitian ini telah mendapatan etika/ethical approval dari Komisi Etik Poltekkes Kemenkes Denpasar dengan No: LB.02.03/EA/KEPK/02962020

\section{SUMBER DANA}

Sumber dana pada penelitian ini adalah DIPA Poltekkes Denpasar tahun 2020.

\section{DAFTAR RUJUKAN}

1. World Health Organization. WHO Global Nutrition Targets 2025: Anaemia Policy Brief. Switzerland: World Health Organization; 2014.

2. WHO. Role of Weekly Iron and Folic Acid Supplementation. Prev Iron Deficneincy Anaemia Adolesc [Internet]. 2011;7-8. Available from: http://apps.searo.who.int/PDS_DOCS /B4770.pdf?ua=1

3. WHO. Global Nutrition Targets 2025 Anaemia policy brief [Internet]. Switzerland: Department of Nutrition for Health and Development WHO; 2012. Available from: http://apps.who.int/iris/bitstream/han dle/10665/148556/WHO_NMH_NH D_14.4_eng.pdf?ua $=1$

4. Kemenkes. Riset Kesehatan Dasar 2013 [Internet]. Jakarta: Badan Penelitian dan Pengembangan 
Kesehatan Departemen Kesehatan Republik Indonesia. Jakarta; 2013. Available from: http://www.depkes.go.id/resources/do wnload/general/Hasil Riskesdas 2013

5. Kementerian Kesehatan Republik Indonesia. Potret Sehat Indonesia dari Riskesdas 2018. Kemenkes RI [Internet]. 2018; (Riskesdas 2013):2018-20. Available from: http://www.depkes.go.id/pdf.php?id= 18110200003

6. WHO. The Global Prevalence of Anaemia in 2011 [Internet]. Switzerland: WHO; 2015. Available from:

http://apps.who.int/iris/bitstream/han dle/10665/177094/9789241564960_e ng.pdf;jsessionid $=676740 \mathrm{C5B} 7 \mathrm{DE} 04$ 04BAB9AC900EE89B9E? sequence= 1

7. Upadhye $\mathrm{J} \mathrm{V}$, Upadhye JJ. Assessment of anaemia in adolescent girls. Int J Reprod Contracept Obs Gynecol [Internet]. 2017;6(7):31137. Available from: www.ijcrog.org/index.php/ijcrog

8. Akib A, Sumarmi S. Kebiasaan Makan Remaja Putri yang Berhubungan dengan Anemia : Kajian Positive Deviance Food Consumption Habits of Female Adolescents Related to Anemia: A Positive Deviance Approach. Amerta Nutr. 2017;1(2):105-16.

9. Tambunan LN, Araya W, Neneng Safitri. Hubungan Tingkat Pengetahuan dengan Sikap Tentang Anemia Defisiensi Besi Dan Dampaknya Terhadap Kesehatan Reproduksi Pada Remaja Putri. J Din Kesehat [Internet]. 2017;7(Desember):22-4. Available from:

http://download.portalgaruda.org/arti cle.php?article $=507521 \& \mathrm{val}=10381$ \&title

10. Shesha T, Chaluvaraj I, Satyanarayana PT. Change in
Knowledge , Attitude and Practice Regarding Anaemia among High School Girls in Rural Bangalore: An Health Educational Interventional Study. Natl J Community Med. 2018;9(5):358-62.

11. Kemenkes. Pedoman pencegahan dan penanggulanngan anemia pada remaja putri dan wanita usia subur (WUS). 2016;14.

12. Kementerian Kesehatan republik Indonesia. Rencana strategis kementerian kesehatan tahun 20152019. Jakarta: Kementerian Kesehatan Republik Indonesi.; 2015.

13. Kementerian Kesehatan Republik Indonesia. Hasil Utama Riskesdas 2018. Jakarta: Badan Penelitian dan Pengembangan Kesehatan Kemenkes RI; 2018.

14. Dinas Kesehatan Provinsi Bali. Profil Kesehatan Bali 2017. Denpasar: Dinas Kesehatan Provinsi Bali; 2018.

15. Agung G, Sriningrat PA, Yukiyatni CD, Ani LS. Prevalensi anemia pada remaja putri di kota Denpasar. EJurnal Med. 2019;8(2):1-6.

16. Hamranani SST, Permatasari D, Subiakni B. Hubungan Pengetahuan dan Sikap dengan Kepatuhan Minum Tablet FE Pada Remaja Putri Kelas X di SMK N 1 Klaten. Triage J Ilmu Keperawatan. 2018;8(1):1-10.

17. Dubik SD, Amegah KE, Alhassan A, Mornah LN, Fiagbe L. Compliance with Weekly Iron and Folic Acid Supplementation and Its Associated Factors among Adolescent Girls in Tamale Metropolis of Ghana. J Nutr Metab. 2019;2019.

18. Hasyim AN, Mutalazimah M, Muwakhidah M. Pengetahuan Risiko, Perilaku Pencegahan Anemia Dan Kadar Hemoglobin Pada Remaja Putri. Profesi (Profesional Islam Media Publ Penelit. 2018;15(2):33.

19. Widiastuti A, Rusmini. Kepatuhan Konsumsi Tablet Tambah Darah Pada Remaja Putri. J Sains 
Kebidanan. 2019;1(1).

20. Nuradhiani A, Briawan D, Dwiriani

CM. Dukungan guru meningkatkan kepatuhan konsumsi tablet tambah darah pada remaja putri di Kota Bogor. J Gizi dan Pangan. 2017;12(3):153-60.

21. P. Stevani Basuki EU. Factors Affecting Iron And Folicacid Consumption Among Adolescents: A Literature Review. Proc Int Conf Appl Sci Heal. 2019;(4):609-12.

22. Noverina D, Dewanti LP, Sitoayu L. Pengaruh explanation video terhadap pengetahuan dan kepatuhan konsumsi tablet tambah darah di SMPN 65 Jakarta Utara. Vol. 4, Darussalam Nutrition Journal. 2020. p. 35.

23. Putri RD, Simanjuntak BY, Kusdalinah K. Pengetahuan Gizi, Pola Makan, dan Kepatuhan Konsumsi Tablet Tambah Darah dengan Kejadian Anemia Remaja Putri. J Kesehat. 2017;8(3):404. 